\title{
Partial sublingual glandectomy with ranula excision: a new conservative method for treatment
}

\author{
In-Kyo Chung ${ }^{1}$, Hyo-Ji Lee ${ }^{1}$, Dae-Seok Hwang ${ }^{1}$, Yong-Deok Kim', \\ Hae-Ryoun Park ${ }^{2}$, Sang-Hun Shin', Uk-Kyu Kim, Jae-Yeol Lee ${ }^{1}$ \\ Departments of ${ }^{1}$ Oral and Maxillofacial Surgery, ${ }^{2}$ Oral and Maxillofacial Pathology, \\ School of Dentistry, Pusan National University, Yangsan, Korea
}

\begin{abstract}
J Korean Assoc Oral Maxillofac Surg 2012;38:160-5)
Objectives: This study evaluated the clinical results of partial sublingual glandectomy accompanying the excision of ranula as new treatment modality.

Materials and Methods: A total of 43 patients who were treated between 1999 and 2007 for oral or plunging ranula were reviewed. All patients were treated surgically by various methods with a total of 55 different procedures performed. Ten cases of partial sublingual glandectomy with excision of the ranula were conducted. All excised specimens were examined. We compared the clinical outcomes resulting from each treatment method.

Results: The recurrence rates for marsupialization, excision of ranula, marsupialization with gauze packing, total excision of sublingual gland and ranula, and partial sublingual glandectomy with excision of ranula were $50 \%, 25 \%, 25 \%, 0 \%$ and $10 \%$, respectively. Of the 10 patients treated by partial sublingual glandectomy with ranula excision, only one experienced recurrence (10\%), i.e., plunging ranula. None of the ranulas contained an epithelial lining, and the excised portion of the feeding sublingual glands showed degenerative changes.

Conclusion: In removal of ranulas, we found that excision of the attached sublingual gland, which removed the feeding portion and degenerative acinar cells, yielded good outcomes. Thus, as a new conservative method for treatment, we recommend partial sublingual glandectomy to accompany excision of the ranula.
\end{abstract}

Key words: Ranula, Sublingual gland, Treatment outcome

\section{Introduction}

A ranula is a mucocele occurring on the floor of the mouth and is derived either from the extravasation of saliva out of the salivary ducts or retention of saliva inside the salivary ducts, originating in the minor salivary gland or the sublingual gland as one of the major salivary glands ${ }^{1,2}$. In general, a ranula is known as an extravasation phenomenon of the sublingual gland ${ }^{3-6}$. It looks like a cystic lesion, but it is a pseudocyst without epithelial lining ${ }^{3,7-12}$. Note, however, that there have been few cases wherein mucus retention cysts

\section{Jae-Yeol Lee}

Department of Oral and Maxillofacial Surgery, Pusan National University Hospital, 179 Gudeok-ro, Seo-gu, Busan 602-739, Korea

TEL: +82-51-240-7432 FAX: +82-51-231-7429

E-mail: id9753153@gmail.com

@) This is an open-access article distributed under the terms of the Creative Commons Attribution Non-Commercial License (http://creativecommons.org/licenses/by-nc/3.0/), which permits unrestricted non-commercial use, distribution, and reproduction in any medium, provided the original work is properly cited. of Rivini and Wharton ducts have been reported ${ }^{1}$. In this case, a true epithelial lining made of the epithelium of the duct was detected. When a ranula spreads out from the posterior inferior area of the mylohyoid muscle to the submental area or cervical area, it is known as a plunging ranula. In general, ranulas appear as a bluish dome-shaped swelling on the floor of the mouth. When mucoceles accumulate in the subcutaneous area or near the epidermis area, a ranula appears as a light bluish color because of epidermal cyanosis and retained saliva in the subcutaneous area. When a ranula exists in the deeper areas, however, the mucosa appears as an ordinary pinkish color.

A ranula does not cause serious symptoms of pain except some discomfort, and it hardly gives rise to any severe clinical manifestation. According to Baurmash ${ }^{1}$, clinical findings such as discomfort in speech, mastication, and swallowing and external swelling differ depending on the size and location of the ranula. In the case of a very large mucocele in the sublingual gland, the tongue may compress 
the ranula during eating and swallowing such that there is interference with the salivary flow of the submandibular gland. When a plunging ranula increases in size, it may cause dyspnea and dysphagia and may expand as far as the mediastinum $^{13}$. There are several surgical methods for the treatment of ranulas, with varying cure rate ${ }^{7,8,14}$. Although a simple technique, marsupialization has been reported to have a high recurrence rate. To minimize any recurrence, Baurmash $^{2}$ proposed marsupialization with gauze packing and suggested that the removal of the entire sublingual gland could be overtreatment in some cases. In contrast, there have been several reports of the extirpation of the entire sublingual gland, recording a relatively high cure rate. Thus, the removal of the entire sublingual gland is proposed to minimize any recurrence ${ }^{7,8,11,14-16}$. Note, however, that the complete removal of the sublingual gland may involve the functional deterioration of the salivary glands and increase the possibility of damage to the Wharton's duct, lingual nerves, and blood vessels ${ }^{6,16}$.

In this research, we have investigated the usefulness of a procedure involving the simultaneous partial removal of a damaged area of the sublingual gland with the excision of the ranula. This method maintains the function of the sublingual gland and minimizes the recurrence rate. Here, we describe partial sublingual glandectomy with the excision of the ranula as a new treatment model and compare it with other surgical procedures.

\section{Materials and Methods}

Retrospective evaluation was performed on 43 consecutive patients diagnosed with ranulas during the period 19992007 at the authors' institution. The patients' ages ranged from 3 to 75 years, with average age of 21 years. A total of

Table 1. Surgical methods and recurrence rates

\begin{tabular}{lccc}
\hline \multicolumn{1}{c}{ Operation type } & $\begin{array}{c}\text { Number of } \\
\text { operation cases }\end{array}$ & $\begin{array}{c}\text { Number of } \\
\text { recurrences }\end{array}$ & $\begin{array}{c}\text { Recurrence } \\
\text { rate }(\%)\end{array}$ \\
\hline $\begin{array}{l}\text { Excision of ranula } \\
\text { Marsupialization }\end{array}$ & 24 & 6 & 25.0 \\
$\begin{array}{l}\text { Marsupialization with } \\
\text { gauze packing }\end{array}$ & 4 & 5 & 50.0 \\
$\begin{array}{l}\text { Total excision of sublingual } \\
\text { gland and ranula }\end{array}$ & 4 & 0 & 0 \\
$\begin{array}{l}\text { Partial sublingual glandectomy } \\
\text { with excision of ranula }\end{array}$ & 10 & 1 & 10.0 \\
Total & 52 & 13 & 25.0 \\
\hline
\end{tabular}

In-Kyo Chung et al: Partial sublingual glandectomy with ranula excision: a new conservative method for treatment. J Korean Assoc Oral Maxillofac Surg 2012
52 surgical treatments were performed on the 43 patients. (Table 1) Mucoceles in areas other than the floor of the mouth and occurrences on the Wharton's duct were excluded. Based on the medical records, we investigated the diagnosis, treatment, status of relapse, and complications. The results of each surgical procedure were reviewed, and we assessed the clinical results of partial sublingual glandectomy with the excision of the ranula in comparison with the other methods used. Histological examinations were performed on all excised specimens. Each ranula was completely excised, except in the case of marsupialization. The follow-up period was from at least six months up to two years.

Among the 43 patients, 10 were treated with partial sublingual glandectomy with excision of the ranula. Surgery was performed under general anesthesia. Elliptical incision was made on the mucosa of the ranula. Meticulous, blunt dissection was performed along with the pseudocyst up to the sublingual gland. When dissection reached the body of the sublingual gland secreting the ranula, the location of the attachment portion of the sublingual gland was confirmed and excised for $1-1.5 \mathrm{~cm}$.(Fig. 1) The resected margin of the sublingual gland was sutured with 4-0 non-absorbable silk, and the incised mucosa was closed using a general method. The other procedures used-except partial glandectomywere carried out using ordinary methods.

\section{Results}

At least 39 and 4 patients were diagnosed with ranulas on the floor of the mouth and plunging ranulas, respectively.

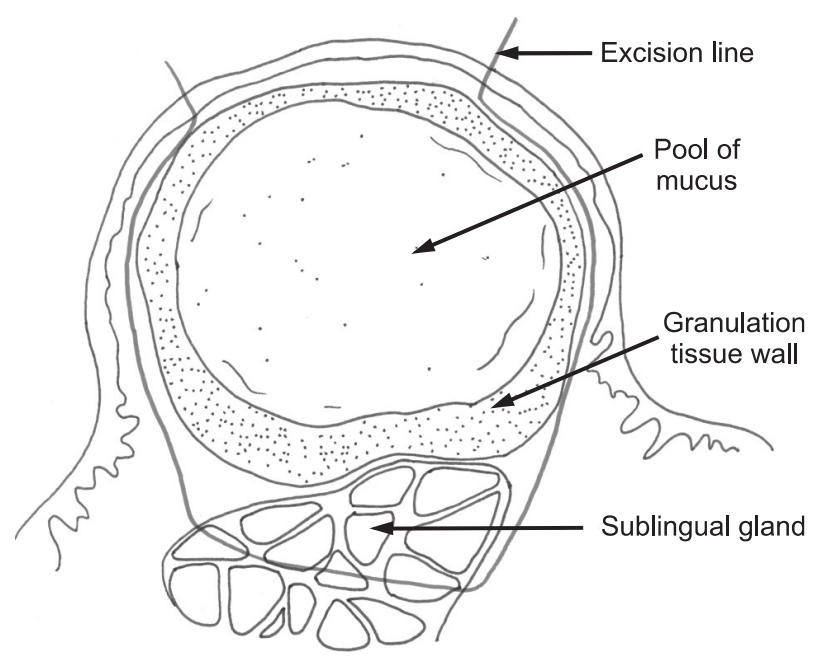

Fig. 1. Partial sublingual glandectomy with excision of ranula. In-Kyo Chung et al: Partial sublingual glandectomy with ranula excision: a new conservative method for treatment. J Korean Assoc Oral Maxillofac Surg 2012 
There were 24 cases of excision of the ranula, 10 cases of marsupialization, 4 cases of marsupialization with gauze packing, 4 cases of total excision of the sublingual gland and ranula, and 10 cases of partial sublingual glandectomy with excision of the ranula. The recurrence rates were $25 \%, 50 \%$, $25 \%, 0 \%$, and $10 \%$, respectively.

Eight patients underwent partial sublingual glandectomy with excision of the ranula as the first operation, and one of the patients suffered from recurrence.(Table 2) This male patient was 3 years old and was diagnosed with a ranula at the first visit. One month after the surgery, the patient had a recurrent lesion. The patient was rediagnosed with a plunging ranula and subsequently treated with total excision of the sublingual gland and ranula.

In two of the patients who were each treated with excision of the ranula and marsupialization in the first surgery, ranulas recurred one month later. These patients were operated on using partial sublingual glandectomy (Fig. 2), and neither suffered from recurrence. The recurrent lesions were treated with partial sublingual glandectomy with excision of the ranula, and the condition was resolved.

In one case of excision of the ranula, the patient complained of parethesia on the ipsilateral side of the tongue immediately after the surgery, but the symptoms were resolved two weeks later with no further treatment. Other than post-operative swelling or discomfort, no other complications were found.

According to the histological tests, no lesions with true epithelial lining were found. The mucus cavity was lined with loose connective tissue and granulation tissue. These showed fibrous tissue, inflammatory cells, foamy histiocytes, and lymphocytes in the connective tissue. Degeneration of acinic cells from partially excised sublingual glands and dilation of the duct were observed.(Fig. 3) Inflammation and degeneration were detected in the sublingual gland adjacent to the ranula.

\section{Discussion}

Ranula is a clinical term denoting a mucocele occurring on the floor of the mouth. The etiology of a ranula is discussed

Table 2. Partial sublingual glandectomy with excision of ranula

\begin{tabular}{|c|c|c|c|c|c|c|}
\hline Case & Gender/age & Dx. & Site & 1st operation & 2 nd operation ${ }^{1}$ & Result \\
\hline 1 & Male/3 & Plunging ranula & Lt. & PSG & TE & $\mathrm{N}$ \\
\hline 2 & Male/5 & Ranula & Lt. & PSG & $\mathrm{N}$ & \\
\hline 3 & Male/6 & Ranula & Rt. & PSG & $\mathrm{N}$ & \\
\hline 4 & Male/8 & Ranula & Rt. & PSG & $\mathrm{N}$ & \\
\hline 5 & Female/8 & Ranula & Lt. & PSG & $\mathrm{N}$ & \\
\hline 6 & Female/8 & Ranula & Rt. & PSG & $\mathrm{N}$ & \\
\hline 7 & Female/14 & Ranula & Rt. & PSG & $\mathrm{N}$ & \\
\hline 8 & Female/75 & Ranula & Rt. & PSG & $\mathrm{N}$ & \\
\hline 9 & Female/22 & Ranula & Rt. & $\mathrm{E}$ & PSG & $\mathrm{N}$ \\
\hline 10 & Female/30 & Ranula & Lt. & M & PSG & $\mathrm{N}$ \\
\hline
\end{tabular}

(Dx.: diagnosis, Lt.: left, Rt.: right, PSG: partial sublingual glandectomy with excision of ranula, E: excision of ranula, M: marsupialization, TE: total excision of sublingual gland and ranula, $\mathrm{N}$ : no recurrence)

${ }^{1}$ in recurrence cases after the 1 st operation.

In-Kyo Chung et al: Partial sublingual glandectomy with ranula excision: a new conservative method for treatment. J Korean Assoc Oral Maxillofac Surg 2012
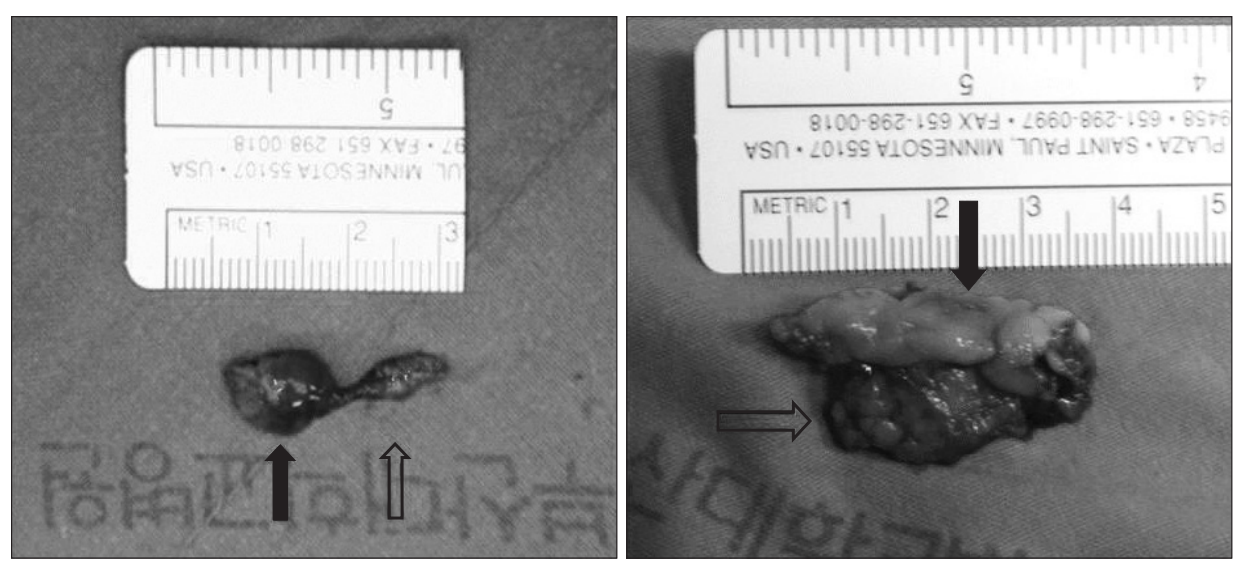

Fig. 2. Gross findings of excised ranula and excised portion of sublingual gland. Solid arrow: ranula, hollow arrow: attached sublingual gland.

In-Kyo Chung et al: Partial sublingual glandectomy with ranula excision: a new conservative method for treatment. J Korean Assoc Oral Maxillofac Surg 2012 

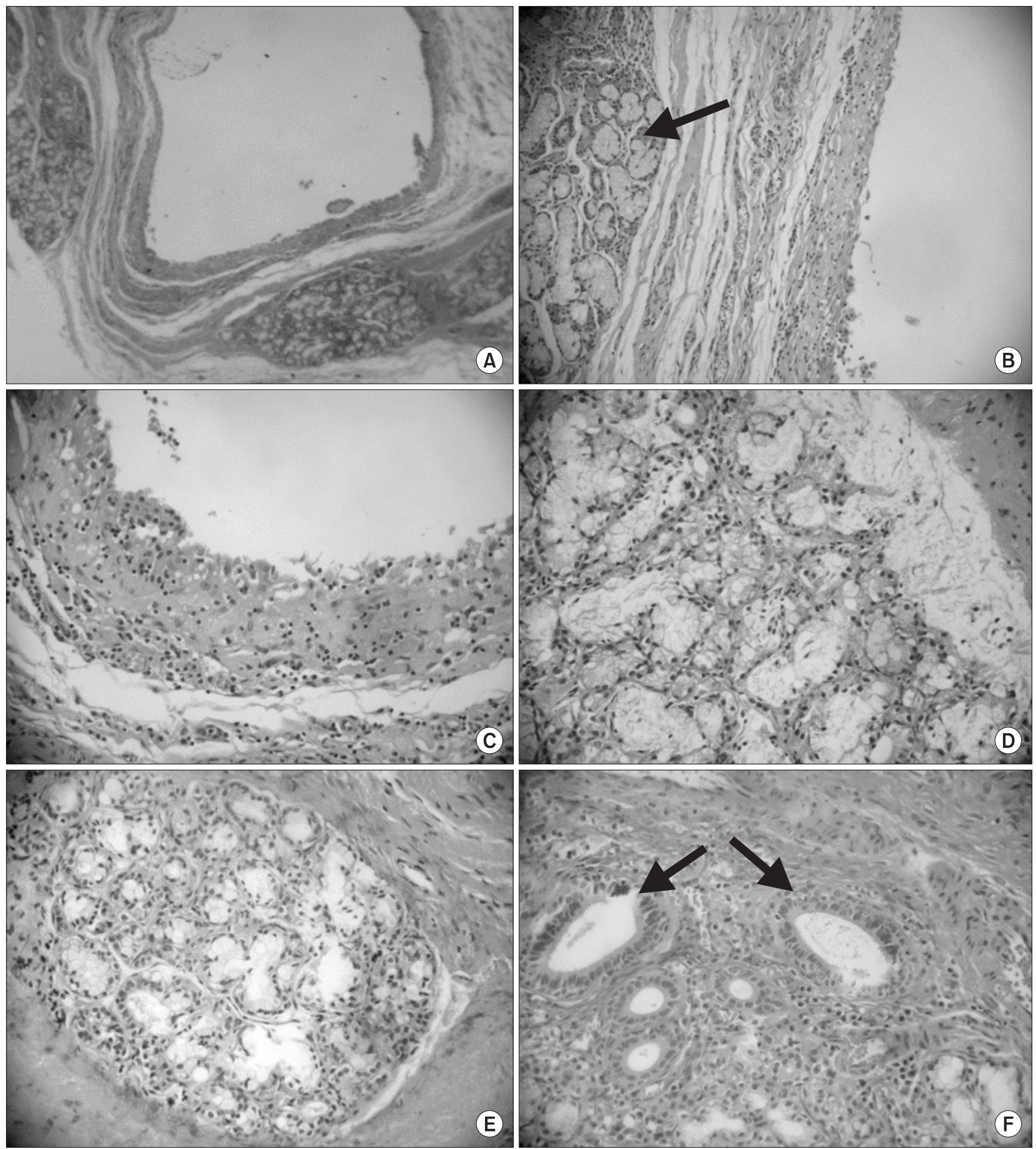

Fig. 3. Histopathologic features of ranula. A, B. A cystic cavity is surrounded by loose connective tissue or granulation tissue (H\&E staining, $A: \times 50, B: \times 120)$. Adjacent feeding sublingual gland (arrow) is seen near the cavity. C. The cystic wall is composed of numerous inflammatory cells, foamy histiocytes, lymphocytes, and fibrous tissue (H\&E staining, $\times 150)$. D, E. In the sublingual gland, acinic cells show degenerative change (H\&E staining, $\times 400)$. F. Ducts (arrows) are dilated and degenerated (H\&E staining, $\times 500)$.

In-Kyo Chung et al: Partial sublingual glandectomy with ranula excision: a new conservative method for treatment. J Korean Assoc Oral Maxillofac Surg 2012

in terms of ductal obstruction and damage of the salivary duct $^{17}$. The retention of mucus and ductal dilation occur with the obstruction of this duct. The result is an epitheliallined cyst. Observation of these cases is rare; the size of the lesion is also small ${ }^{8}$. The common form of a ranula is a pseudocyst derived from the extravasation of the sublingual gland $^{3-17}$. The reason for the extravasation is considered to be trauma to the sublingual gland and related structure ${ }^{1,7,8}$. 
Table 3. Recurrence rates (\%) and number of cases inliterature

\begin{tabular}{|c|c|c|c|c|c|}
\hline & I\&D & M & MP & $\mathrm{E}$ & ESG \\
\hline Crysdale et al. $^{8}$ & $100(4)$ & $61(19)$ & $0(2)$ & $0(4)$ & $0(11)$ \\
\hline Yoshimura et al. ${ }^{7}$ & - & $36.4(22)$ & - & $25(4)$ & $0(9)$ \\
\hline Zhao et al. ${ }^{14}$ & - & $66.67(9)$ & - & $57.69(26)$ & $1.05-1.55(415)$ \\
\hline Chidzonga and Mahomva ${ }^{19}$ & - & $20(10)$ & - & - & $0(73)$ \\
\hline
\end{tabular}

(I\&D: incision and drainage, M: marsupialization, MP: marsupialization with gauze packing, E: excision of ranula, ESG: excision of sublingual gland)

Values are presented as \% (number).

In-Kyo Chung et al: Partial sublingual glandectomy with ranula excision: a new conservative method for treatment. J Korean Assoc Oral Maxillofac Surg 2012

When the acinic cells are damaged by trauma, saliva leaks into adjacent tissue and forms a cystic cavity lined by granulation tissue surrounded by loose connective tissue. Many studies have confirmed that the excised ranula has no true epithelial lining ${ }^{3,7-11}$. The etiology for a ranula is still not clear, however ${ }^{1,18}$. In this research, no lesions with true epithelial lining were observed; thus, ranulas are thought to be an extravasation phenomenon of the sublingual gland.

There have been several methods used for the treatment of ranulas, but proper modality is still a subject of debate because of the tendency toward recurrence. The recurrence rates in literature are summarized in Table 3 , decreasing in the following order: marsupialization, excision of ranula, and excision of the sublingual gland. Zhao et al..$^{14}$ stated that the recurrence rates of ranulas were not related to the patterns of lesion but were closely related to the method of the surgical procedure used. Crysdale et al. ${ }^{8}$ suggested excision of the sublingual gland for ranulas $>1 \mathrm{~cm}$. Catone et al. ${ }^{11}$ and Bridger et al. ${ }^{15}$ proposed excision of the sublingual gland as the primary treatment for all ranulas regardless of size.

Because of its simplicity and complications after the excision of the sublingual gland, many clinicians prefer marsupialization as the first treatment ${ }^{16,19}$. Complications associated with the surgical management of ranulas have been investigated by Zhao et al. ${ }^{16}$. According to them, the most frequent complications are the recurrence of lesion and numbness of the tongue due to damage to the lingual nerve. Damage to the Wharton duct, hemorrhaging, hematoma, wound dehiscence, and infection have been reported as well. Recurrence was frequent in the marsupialization and excision of the ranula. Injury to adjacent tissue was related mainly to the excision of the sublingual gland. Note, however, that these complications after the excision of the ranula were temporary and were resolved within a given timeframe. Thus, to minimize recurrence as the most common complication, the removal of the sublingual gland has been suggested.

Some clinicians are still skeptical as to the total removal of the sublingual gland. Baurmash ${ }^{5}$ insists that the total excision of the sublingual gland is not appropriate for smallsized ranulas and suggests a modified marsupialization with gauze packing. Baurmash used this method on 12 cases, with 1 case of recurrence reported. According to Baurmash, however, marsupialization cannot resolve ranulas associated with the deep part of the sublingual gland. In addition, marsupialization (either once or repeated) can cause fibrosis of the upper side; thus, mucus can be induced in the lower part of the lesion, resulting in a plunging ranula in case of recurrence ${ }^{15}$.

To summarize the viewpoint of the healing process, the previously reviewed treatment method can be categorized as follows: chronic fistulization of the lesion; sealing of the feeder base; excision of the ranula only, and; removal of the sublingual salivary gland as the origin. Marsupialization forms a chronic fistula between the mucus secretion part and the oral cavity. Note, however, that most ranulas do not have a true epithelial lining; thus, a chronic fistula cannot be established ${ }^{8,11}$. Consequently, there is recurrence with the healing of the oral epithelium. The technique of sealing the feeder base induces atrophy and fibrosis of the damaged part of the sublingual gland. Marsupialization with gauze packing, cauterization using $\mathrm{CO}_{2}$ laser ${ }^{20,21}$, and injection of picibanil (OK$432)^{22,23}$ fall under this category. Marsupialization accompanied by gauze packing maintains a channel to the oral cavity and allows time for fibrosis of the mucus secretion area; hence its lower recurrence rate than simple marsupialization. Similarly, fibrosis and sclerosis of the mucus secretion part are induced by $\mathrm{CO}_{2}$ laser and injection of OK-432. In this trial, however, the possibility of recurrence still exists because the damaged part of the sublingual gland is not excised. The procedure for the excision of the ranula only removes the cyst, so it has a blind point, i.e., it can miss the feeder gland. The removal of the sublingual gland as the source of the pseudocyst is a radical treatment; hence its potential complications.

Partial sublingual glandectomy with excision of the ranula 
can satisfy many of the requirements discussed above. First, it removes the ranula lesion as well as the origin of the lesion by excising the mucus-supplying part of the sublingual gland. Suturing of the excised margin of the sublingual gland is intended to seal the feeder base. Furthermore, the sublingual gland has several secretion ducts that open independently; thus, functional recovery of the sublingual gland can be expected even after the excision of part of the sublingual gland. In addition, it is noninvasive compared to the total extirpation of the sublingual gland, and so it is expected to have fewer complications.

Partial glandectomy is mainly applied to operations on the parotid gland, and superficial parotidectomy is practiced widely. Partial superficial parotidectomy has been introduced as a more conservative method than superficial parotidectomy ${ }^{24}$. This partial salivary glandectomy is based on the regenerative ability of the salivary glands, and the healing procedure of damaged salivary glands of rodents has been reported $^{25,26}$. Note, however, that there have been no reports on partial sublingual glandectomy. Similar to the regeneration of parotid glands, sublingual glands are expected to go through a similar healing procedure.

\section{Conclusion}

In this study, we have shown that patients who underwent partial sublingual glandectomy with the excision of a ranula recovered without any noticeable complication and with low recurrence rate.

Therefore, partial sublingual glandectomy with excision of the ranula has value in clinical practice as a new conservative method. Nonetheless, the number of cases in this research is still small, so further investigations are needed. Moreover, further research on factors such as the amount of excision, functional recovery, and change in the pattern of sublingual glands after partial excision is required.

\section{References}

1. Baurmash HD. Mucoceles and ranulas. J Oral Maxillofac Surg 2003;61:369-78.

2. Baurmash HD. A case against sublingual gland removal as primary treatment of ranulas. J Oral Maxillofac Surg 2007;65:117-21.

3. Kurabayashi T, Ida M, Yasumoto M, Ohbayashi N, Yoshino N,
Tetsumura A, et al. MRI of ranulas. Neuroradiology 2000;42:91722.

4. Shelley MJ, Yeung KH, Bowley NB, Sneddon KJ. A rare case of an extensive plunging ranula: discussion of imaging, diagnosis, and management. Oral Surg Oral Med Oral Pathol Oral Radiol Endod 2002;93:743-6.

5. Baurmash HD. Marsupialization for treatment of oral ranula: a second look at the procedure. J Oral Maxillofac Surg 1992;50: 1274-9.

6. Baurmash HD. Treating oral ranula: another case against blanket removal of the sublingual gland. Br J Oral Maxillofac Surg 2001;39:217-20

7. Yoshimura Y, Obara S, Kondoh T, Naitoh S. A comparison of three methods used for treatment of ranula. J Oral Maxillofac Surg 1995;53:280-2.

8. Crysdale WS, Mendelsohn JD, Conley S. Ranulas--mucoceles of the oral cavity: experience in 26 children. Laryngoscope 1988;98:296-8.

9. Galloway RH, Gross PD, Thompson SH, Patterson AL. Pathogenesis and treatment of ranula: report of three cases. J Oral Maxillofac Surg 1989;47:299-302.

10. Morita Y, Sato K, Kawana M, Takahasi S, Ikarashi F. Treatment of ranula--excision of the sublingual gland versus marsupialization. Auris Nasus Larynx 2003;30:311-4.

11. Catone GA, Merrill RG, Henny FA. Sublingual gland mucusescape phenomenon--treatment by excision of sublingual gland. J Oral Surg 1969;27:774-86.

12. Barnes L. Surgical pathology of the head and neck. 1st ed. New York: Marcel Dekker; 1985:1297-301.

13. Marx RE, Stern D. Oral and maxillofacial pathology. Illinois: Quintessence Publishing; 2003:511.

14. Zhao YF, Jia Y, Chen XM, Zhang WF. Clinical review of 580 ranulas. Oral Surg Oral Med Oral Pathol Oral Radiol Endod 2004;98:281-7.

15. Bridger AG, Carter P, Bridger GP. Plunging ranula: literature review and report of three cases. Aust N Z J Surg 1989;59:945-8.

16. Zhao YF, Jia J, Jia Y. Complications associated with surgical management of ranulas. J Oral Maxillofac Surg 2005;63:51-4.

17. Quick CA, Lowell SH. Ranula and the sublingual salivary glands. Arch Otolaryngol 1977;103:397-400.

18. Harrison JD, Garrett JR. An ultrastructural and histochemical study of a naturally occurring salivary mucocele in a cat. J Comp Pathol 1975;85:411-6.

19. Chidzonga MM, Mahomva L. Ranula: experience with 83 cases in Zimbabwe. J Oral Maxillofac Surg 2007;65:79-82.

20. Frame JW. Removal of oral soft tissue pathology with the $\mathrm{CO} 2$ laser. J Oral Maxillofac Surg 1985;43:850-5.

21. Mintz S, Barak S, Horowitz I. Carbon dioxide laser excision and vaporization of nonplunging ranulas: a comparison of two treatment protocols. J Oral Maxillofac Surg 1994;52:370-2.

22. Woo JS, Hwang SJ, Lee HM. Recurrent plunging ranula treated with OK-432. Eur Arch Otorhinolaryngol 2003;260:226-8.

23. Fukase S, Ohta N, Inamura K, Aoyagi M. Treatment of ranula wth intracystic injection of the streptococcal preparation OK-432. Ann Otol Rhinol Laryngol 2003;112:214-20.

24. Martis C. Parotid benign tumors: comments on surgical treatment of 263 cases. Int J Oral Surg 1983;12:211-20.

25. Milstein BB. Regeneration in the submaxillary gland of the rat. $\mathrm{Br}$ J Exp Pathol 1950;31:664-9.

26. Hanks CT, Chaudhry AP. Regeneration of rat submandibular gland following partial extirpation. A light and electron microscopic study. Am J Anat 1971;130:195-207. 